\title{
IGUAÇU (IAC-21) E ARAGUAIA (IAC-22): CULTIVARES DE TRIGO DE SEQUEIRO PARA O ESTADO DE SÃO PAULO (1)
}

\author{
JOÃO CARLOS FELICIO $\left({ }^{2,5}\right)$, CARLOS EDUARDO DE OLIVEIRA CAMARGO $\left({ }^{2,5}\right)$, \\ BENEDITO DE CAMARGO BARROS $\left({ }^{3,5}\right)$ e POLICARPO VITTI $(4,5)$
}

\begin{abstract}
RESUMO
Em experimentos localizados nas principais regioes tritícolas paulistas, comparou-se a produtividade e as reaçoes aos agentes de ferrugem-do-colmo e da folha, bem como as qualidades industriais de panificaçao de dois novos cultivares de trigo - Iguaçu (IAC-21) e Araguaia (IAC-22) - provenientes de cruzamentos artificiais e obtidos por seleção por método genealógico, com os cultivares BH-1146 e Maringá (IAC-5). A produção média de grãos do 'Iguaçu' foi $8 \%$ e $12 \%$ estatisticamente superior respectivamente aos cultivares testemunhas, e o 'Araguaia' superou-os em 5 e 14\%. Os novos cultivares apresentaram, ao longo dos cinco anos de estudo, menores níveis de infecção de ferrugem-do-colmo (Puccinia graminis f. sp. tritici) que as testemunhas, sobressaindo-se o 'Araguaia', com baixíssimos niveis de infecção. Os novos cultivares, bem como as testemunhas, mostraram reaçoes médias para ferrugem-da-folha. Nos ensaios de panificação a farinha do 'Araguaia', de maneira geral, exibiu melhor potencial panificável que a do Iguaçu, sendo ambas levemente superiores à farinha de trigo comercial.
\end{abstract}

Termos de indexação: culturas de sequeiro; produtividade; resistência às ferrugens; raças físiológicas de ferrugens; características panificáveis.

( ${ }^{1}$ Com verba suplementar do Acordo do Trigo entre as Cooperativas de Produtores Rurais do Vale do Paranapanema e a Secretaria de Agricultura e Abastecimento, por intermédio do Instituto Agronômico. Recebido para publicação em 19 de dezembro de 1983.

$\left({ }^{2}\right)$ Seção de Arroz e Cereais de Inverno, Instituto Agronómico (IAC), Caixa Postal 28, 13100 Campinas (SP).

(3) Seção de Doenças das Plantas Alimentícias Básicas e Olerícolas, Instituto Biológico.

( $\left.{ }^{4}\right)$ Seção de Cereais, Farinhas e Panificação, Instituto de Tecnologia de Alimentos, 13100 Campinas (SP).

${ }^{5}$ ) Com bolsa de suplemen taçäo do CNPq.

(6) Os autores agradecem à Dra Elisa T. Coelho, do Centro Nacional de Pesquisa de Trigo, a colaboração na identificação das raças de ferrugem-do-colmo. 


\section{INTRODUÇĀO}

A criação de varidades de trigo (COELHO, 1982) teve o seu início no Brasil em 1914, quando Jorge Polyssu selecionou em Nova Tirol, Paraná, a partir de sementes provenientes de Guaporé (RS), um trigo que levou seu nome, Polyssu, e que, apos ser resselecionado na Estação Experimental de Ponta Grossa, recebeu a denominação de PG 1.

Em 1928, o geneticista Iwar Beckman orientou a primeira tentativa oficial para o lançamento de uma variedade adequada para as extensas zonas do Sul do Brasil (TEIXEIRA, 1958). Entretanto, somente em 1945, com o lançamento da variedade Frontana (COELHO, 1982), novas perspectivas se abriram à triticultura nacional, permitindo a mecanização da lavoura de trigo, proporcionando aumento da área cultivada de dez vezes em dez anos.

A falta de cultivares resistentes à ferrugem-do-colmo e adaptados às condiçðes do solo paulista foram os principais insucessos na região Sul do Estado da cultura, que chegou a ser esquecida por bom período de anos (BAYMA, 1960).

A ferrugem-do-colmo (Puccinia graminis tritici) causou grandes epidemias nos Estados Unidos em 1935 e 1937 (ALLARD, 1960) pela ocorrência da raça 56 e da raça $15 \mathrm{~B}$ nos anos 50 , com grandes danos aos trigais. Uma vez que uma nova raça se estabelece em uma região tritícola, sua prevalência é função das variedades cultivadas.

No Brasil, a raça 17 da ferrugem-do-colmo foi a predominante de 1949 a 1965. No período 1966-1970 e 1971-1973, os biótipos 17/63 e 15/ 65 tornaram-se mais prevalentes (BARCELLOS, 1982).

O Instituto Agronomico, mediante trabalhos de melhoramento genético, vem selecionando novos cultivares de trigo (FELÍCIO et alii, 1983) mais adaptados às condiçðes de sequeiro paulistas, entre eles: IAC-17 (Maracaí) e IAC-1 8 (Xavantes).

O presente trabalho tem por objetivo estudar o comportamento de dois novos cultivares de trigo: Iguaçu (IAC-21) e Araguaia (IAC-22) para as regioes de sequeiro do Estado de São Paulo, ao norte do paralelo $24 \mathrm{~S}$.

\section{MATERIAL E MÉTODOS}

O cultivar Iguaçu (IAC-21), obtido pelo método genealógico (Pedigree) (ALLARD, 1960) originou-se do híbrido 71/839 (Siete Cerros x C-17), sendo o 'Siete Cerros' originário do cruzamento Penjamo-62 " $\mathrm{S}$ " $\mathrm{x}$ Gaboto 55, proveniente do México, e o C-17 (Lagoa Vermelha), oriundo do cruzamento Veranópolis $\mathrm{x}$ (Marroquim $\mathrm{x}$ Newthach). 
O cultivar Araguaia (IAC-22), também obtido pelo método genealógico, originou-se do híbrido $71 / 732$ (Pel 21414-66 x IAC-5). O 'Pel 21414 66' foi introduzido do Instituto de Pesquisa Agropecuária do Sul (IPEAS), Pelotas (RS). O 'IAC-5' (Maringá), oriundo da progênie 16494, originou-se do híbrido entre a progênie 7124 e a variedade Polyssu (PG 1), em 1956, na Estação Experimental de Capão Bonito. A 7124 resultou do cruzamento 'Frontana' x 'Kenya 58' em 1951 (CAMARGO, 1972).

No quadro 1, observam-se as características agronômicas determinadas dos cultivares Iguaçu e Araguaia em comparação com aqueles utilizados como testemunhas, BH-1146 e IAC-5: altura das plantas, índice de perfilhamento e acamamento, ciclo em dias da emergência da plântula até a maturação completa, cor das aurículas, posição das folhas, cor da panícula, presença de aristas, forma da espiga, comprimento das panículas, número de espiguetas por panícula, número de grãos por panícula, cor e comprimento dos grãos, largura e espessura dos grãos e reação à tolerância à toxicidade de $\mathrm{Al}^{3+}$.

A altura da planta de cada cultivar foi medida levando em consideração a distância do nível do solo ao ápice da espiga, mantendo-se as plantas esticadas, incluindo as aristas.

Para a determinação da tolerância ao $\mathrm{Al}^{3+}$, foi empregada a técnica descrita por CAMARGO \& OLIVEIRA (1981) que consiste no teste em solução nutritiva contendo, respectivamente, $0,1,3,6$ e $10 \mathrm{mg} /$ litro de alumínio na forma de $\mathrm{Al}_{2}\left(\mathrm{SO}_{4}\right)_{3} .18 \mathrm{H}_{2} \mathrm{O}$.

Foram instalados no período $1978-1982$ nas regiões tritícolas paulistas, dois grupos de experimentos. O primeiro, num total de 28 experimentos, foi composto pelo 'Iguaçu' mais os cultivares testemunhas Maringá e BH-1 146, empregando-se o delineamento de blocos casualizados com quatro repetiçठes por local, e, o segundo, compreendendo 25 experimentos, pelo 'Araguaia' e pelas mesmas testemunhas, utilizando-se o mesmo delineamento, porém com três repetiçoes por local. Independentemente do grupo de experimentos, cada parcela foi formada de cinco linhas de $5 \mathrm{~m}$ de comprimento, espaçadas de $0,20 \mathrm{~cm}$ en tre si, com uma separação lateral entre as parcelas de $0,60 \mathrm{~m}$. Procedeu-se à semeadura com 80 sementes viáveis por metro de sulco, sendo efetuada a colheita de área total das parcelas, ou seja, $5 \mathrm{~m}^{2}$. Para as comparaçðes das médias das produçðes de grãos transformados em quilograma/hectare empregou-se o teste de Duncan a 5\% (GOMES, 1963).

Todos os experimentos receberam adubação a lanço, constante de $30 \mathrm{~kg}$ de $\mathrm{N}$ por hectare, $90 \mathrm{~kg}$ de $\mathrm{P}_{2} \mathrm{O}_{5}$ por hectare e $20 \mathrm{~kg}$ de $\mathrm{K}_{2} \mathrm{O}$ por hectare nas formas de sulfato de amônio, superfosfato simples e cloreto de potássio respectivamente. 


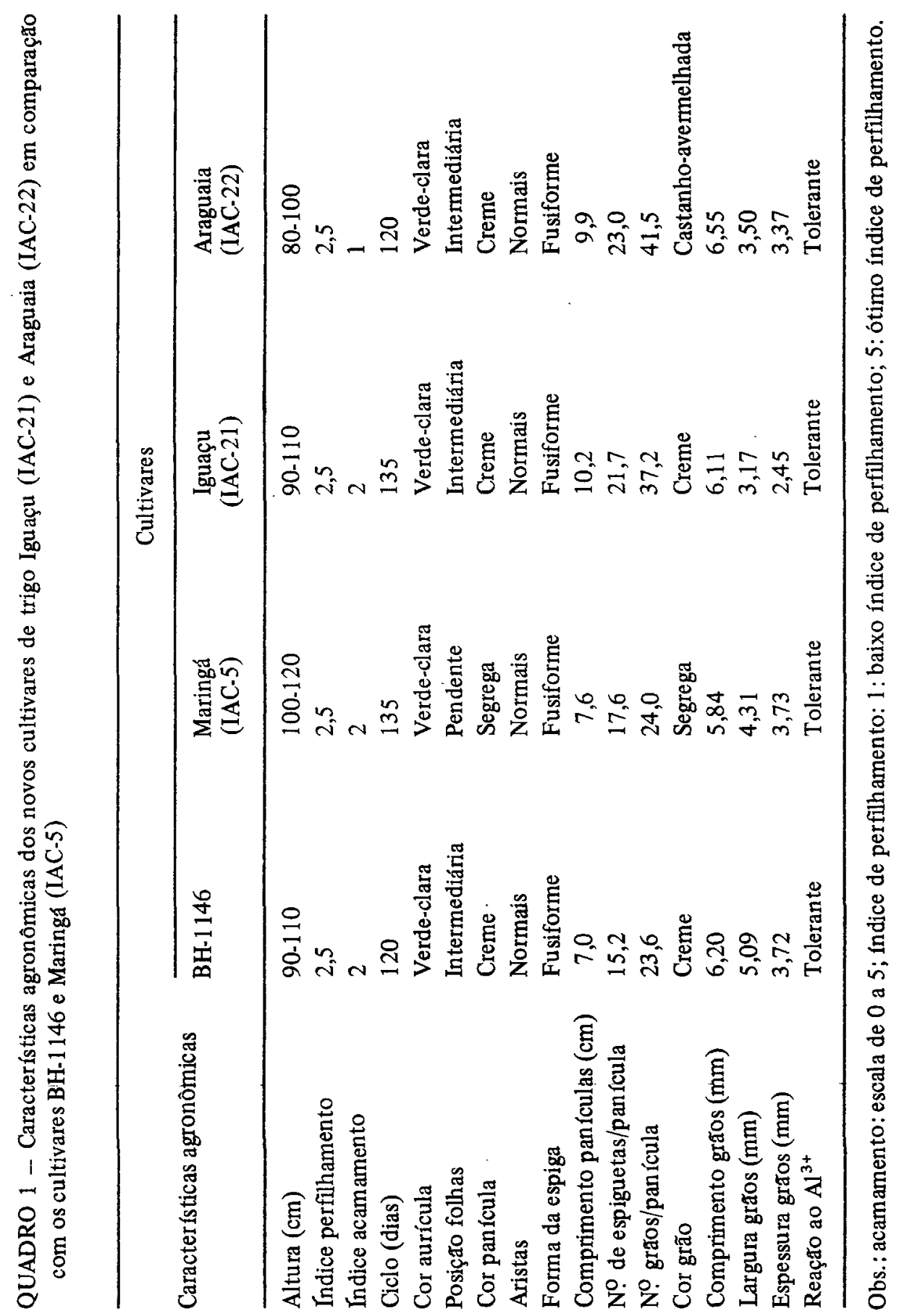


Para o estudo do comportamento dos cultivares em relação à ferrugem-do-colmo (Puccinia graminis f. sp. tritici) e ferrugem-da-folha (Puccinia recondita f. sp. tritici), foram feitas avaliaçoes em plântulas no Centro Nacional de Pesquisa de Trigo, de acordo com critérios apresentados no quadro 2 e em plantas adultas em condição de campo (Região Sul e Vale do Paranapanema), usando-se a escala modificada de Cobb, empregada no Internacional Rust Nursery e utilizada por SCHRAM et alii (1974), a qual é composta por um número estimativo de ataque da moléstia no colmo e na folha, acrescido de letra simbolizando o tipo de reação: $\mathrm{S}=$ suscetível; $\mathrm{MS}=$ moderadamente suscetivel; $\mathbf{M}=$ intermediário; $\mathrm{MR}=$ moderadamente resistente; $\mathrm{R}=$ resistente (quadros 3 e 4).

Os grãos de trigo dos cultivares IAC-21 e IAC-22 foram submetidos inicialmente a testes de moagem, para determinação das características de rendimento. Utilizou-se, para tal, o moinho piloto Bühler, modelo MLU-202, trabalhando-se com $5 \mathrm{~kg}$ de grãos para cada ensaio de moagem.

Os grãos tiveram sua umidade acertada de acordo com a metodologia oficial (ARBEITSGEMEINSCHALT, 1971). Na moagem, determinou-se o rendimento em farinha, farelo grosso e farelo fino.

As farinhas obtidas da moagem foram submetidas a análises de ordem física no farinógrafo, amilógrafo e extensógrafo, segundo métodos da AACC (1969). O teor e a qualidade do glúten, "falling number", teste de sedimentação e teor de cinzas foram determinados segundo BAR (1982). O expansograma foi determinado segundo método oficial (ARBEITSGEMEINSCHALT, 1971).

Para os testes de panificação, utilizou-se a formulação descrita em VITTI et alii (1982). Preparou-se o pão do tipo de 80 gramas de massa por unidade. Compararam-se os pães com aqueles preparados com farinha de trigo comercial.

O preparo dos pães tipo francês seguiu metodologia descrita por VITTI et alii (1980), e sua avaliação foi efetuada de acordo com VITTI et alii (1982).

\section{RESULTADOS E DISCUSSÃO}

As médias de produtividade de grãos dos dois grupos de experimentos compostos pelos cultivares IAC-21 (Iguaçu) e IAC-22 (Araguaia), estudados no período 1978-1982, em ensaios conduzidos em diferentes regióes tritícolas paulistas, encontram-se no quadro 5 . O cultivar Iguaçu produziu em média $1.429 \mathrm{~kg} / \mathrm{ha}$, superior às médias de produção dos cultivares $\mathrm{BH}$ - 


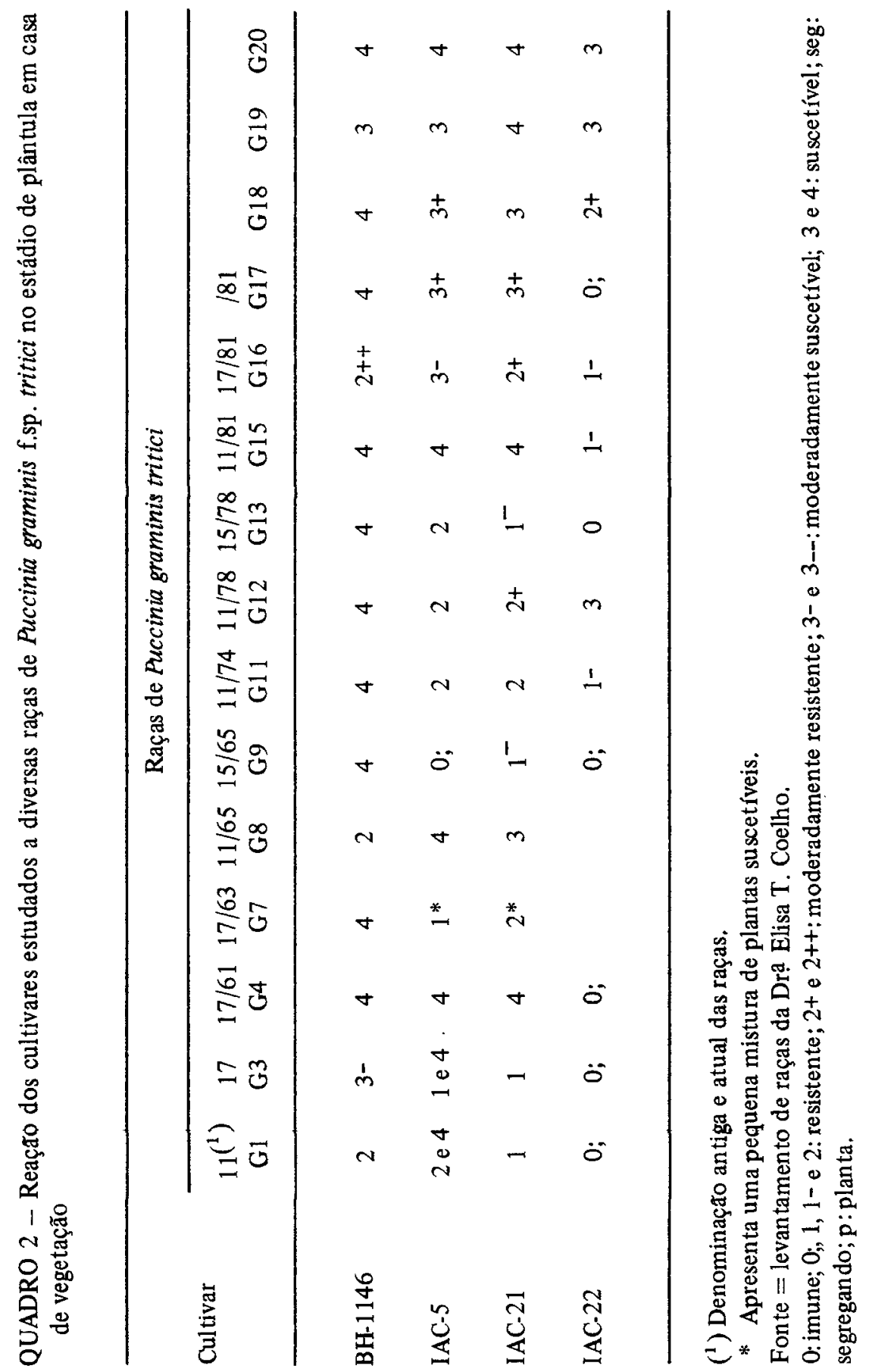



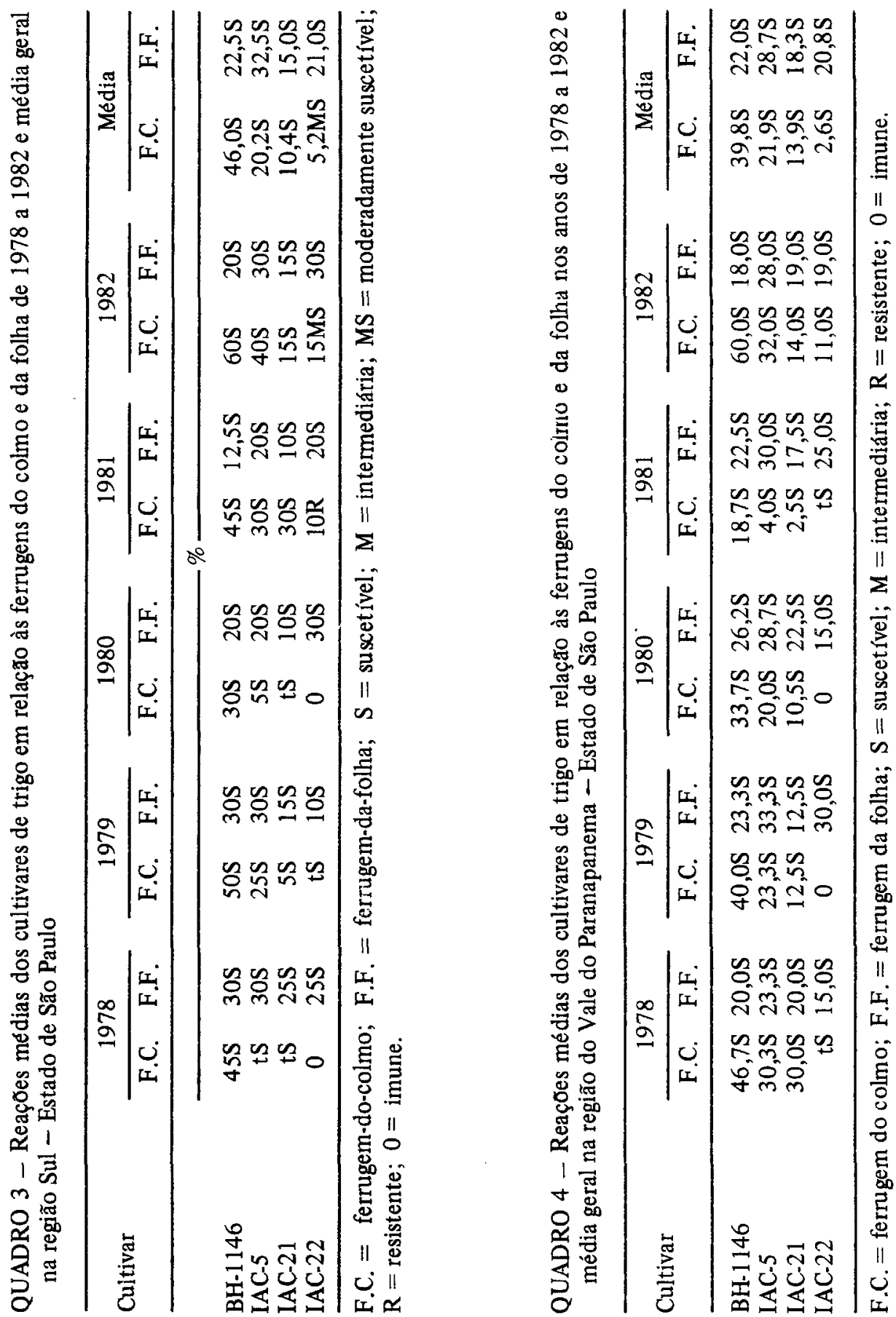
-1146 e IAC-5, respectivamente de 1.323 e $1.275 \mathrm{~kg} / \mathrm{ha}$. Esses dados representam uma produtividade superior de $8 \%$ e $12 \%$ do 'Iguaçu' pelo teste de Duncan em relação às duas testemunhas. $O$ 'Araguaia' apresentou uma produção média de $1.590 \mathrm{~kg} /$ ha nesse período, que comparada aos $1.512 \mathrm{e}$ $1.393 \mathrm{~kg} / \mathrm{ha}$ dos cultivares $\mathrm{BH}-1146 \mathrm{e}$ IAC-5 respectivamente, representa um aumento de produtividade de $5 \%$ e $14 \%$, superior pelo teste de Duncan às produçðes das testemunhas.

As produtividades das duas testemunhas não apresentaram diferenças estatísticas pelo teste de Duncan nas análises conjuntas dos experimentos em blocos ao acaso com tratamentos comuns.

Sendo os dados de produção apresentados em termos de produçбes médias, verifica-se que as variaçбes de produtividade no período estudado nas regiões tritícolas em 28 experimentos foram de 924 a $1.914,791$ a 1.841 e 736 a $2.022 \mathrm{~kg} / \mathrm{ha}$ para os cultivares IAC- 21 , IAC-5 e BH-1146 respectivamente.

Para o cultıvar IAC-22, a variação ocorrida em 25 experimentos foi de 908 a $2.207 \mathrm{~kg} / \mathrm{ha}$ e, para o IAC-5 e BH-1146, respectivamente de 842 a 2.004 e de 740 a $2.081 \mathrm{~kg} / \mathrm{ha}$.

Com relação à resistência dos novos cultivares à ferrugem-do-colmo, conforme pode ser verificado no quadro 2 , o cultivar IAC-22 apresenta resistência às raças G1, G3, G4, G9, G11, G15, G16 e G17, moderada resistência à raça G18, suscetibilidade às raças G12, G19 e G20 e imunidade à raça G13. O cultivar IAC-21 apresenta resistência às raças $G 1, G 3, G 7, G 9, G 11$ e G13, moderada resistência para G12 e G16, com suscetibilidade às raças G4, G8, G15, G17, G18, G19 e G20 (COELHO, 1983).

Em condições de campo, os novos cultivares avaliados nos cinco anos para o grau de infecçāo de ferrugem-do-colmo, mostraram, de modo geral, médias inferiores às apresentadas pelas testemunhas BH-1146 e IAC-5, tanto na região Sul como no Vale do Paranapanema. Os níveis de infecção alcançados pelos cultivares controles foram considerados altos, principalmente em 1978, 1979 e 1982. Pelo quadro 3, pode-se observar que o cultivar IAC-21 manteve baixos níveis de infecção (tS a 5S) até 1980, passando a partir de 1981 a apresentar niveis superiores (30S), provavelmente devido ao incremento de outras raças na região Sul. Entretanto, o IAC-22 permaneceu com os baixos índices de infecção. Na região do Vale do Paranapanema, o grau de severidade da ferrugem-do-colmo, no período estudado, foi menor que na região Sul nos dois novos cultivares, com grande vantagem para o cultivar IAC-22 (quadro 4).

Para ferrugem-da-folha, os níveis de infecção alcançados pelos dois novos cultivares estiveram bem próximos aos das testemunhas, demonstrando suscetibilidade semelhante frente a esse patógeno. Também em testes em 


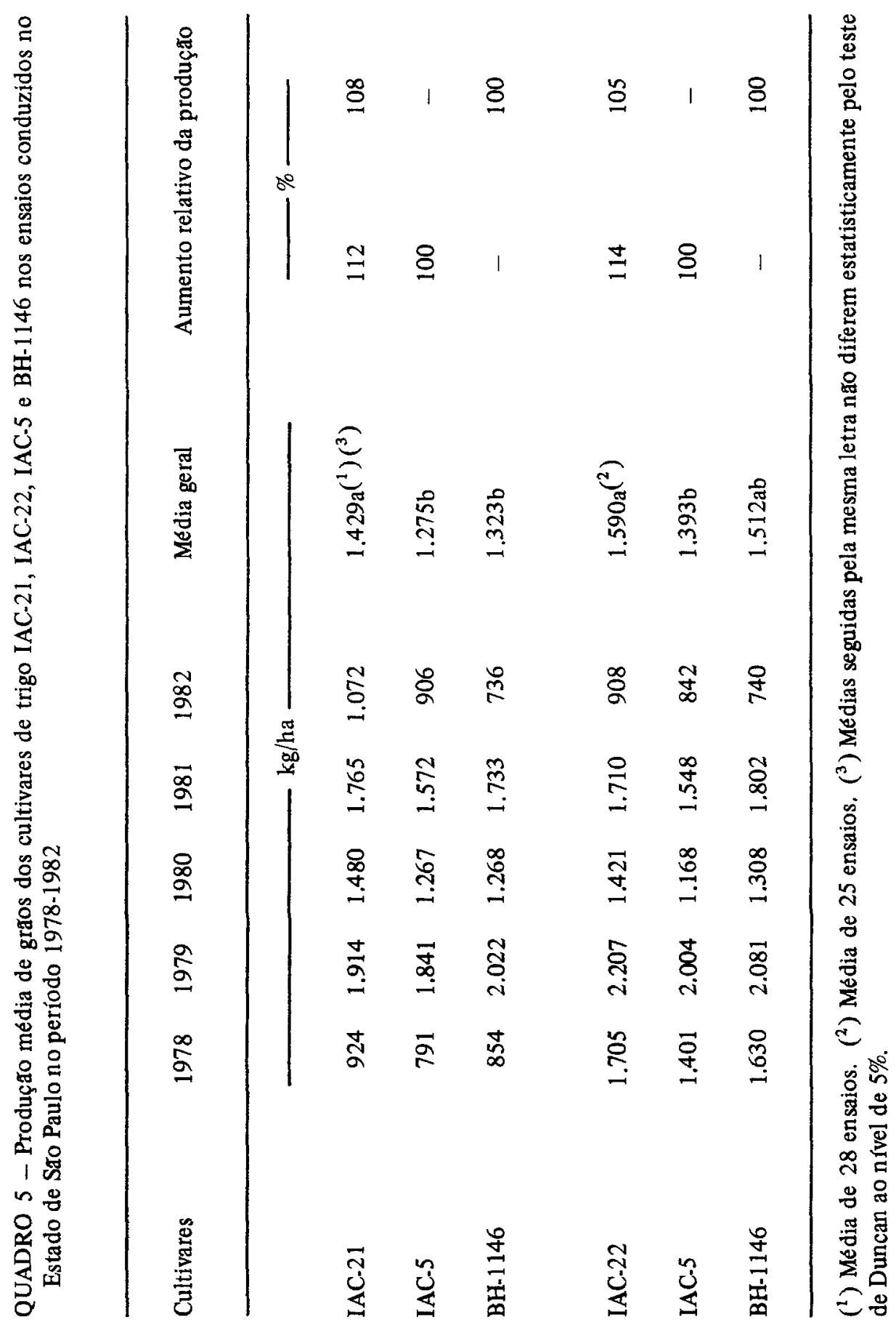


casa de vegetação, demonstraram suscetibilidade às raças prevalecentes nas condiçð̄es paulistas.

A moagem de grãos dos cultivares IAC-21 e IAC-22 no moinho piloto Bühler propiciou-lhes rendimento de $63,3 \%$ e $60,7 \%$ respectivamente (Quadro 6), valores considerados baixos se comparados aos trigos americanos ou canadenses. Deve-se salientar, entretanto, que normalmente os cultivares de trigo nacionais, devido às próprias características intrínsecas, apresentam dificuldades de moagem. Com relação às características do glúten, teor e qualidade, o cultivar IAC-21 foi levemente superior, mostrando também valores de sedimentação mais elevados (Quadro 6). O "falling number", que está relacionado à atividade enzimática da farinha, mostrou-se melhor para $o$ cultivar IAC-21, pois, quanto menor esse parâmetro, maior atividade enzimática tem a farinha. Evidentemente, isso é válido até dados próximos a $200 \mathrm{se}$ gundos: abaixo desse valor, o excesso de atividade enzimática pode ser prejudicial à qualidade do pão preparado com a farinha, pois o miolo do produto seria demasiadamente úmido e pegajoso.

QUADRO 6 - Caracteristicas físicas da farinha de trigo dos cultivares IAC-21 e IAC-22

\begin{tabular}{lccccc}
\hline Amostra & R.M. & T.G.U. & Q.G. & F.N. & Sed. \\
\hline & $\%$ & $\%$ & $\mathrm{~cm}^{3}$ & $\mathrm{~s}$ & $\mathrm{~cm}^{3}$ \\
IAC-21 & 63,3 & 32,6 & 13 & 501 & 27 \\
IAC-22 & 60,7 & 34,2 & 9 & 678 & 24 \\
\hline
\end{tabular}

R.M. = rendimento em moagem; T.G.U. = teor de gluten úmido; Q.G. = qualidade de glúten; F.N. = "falling number"; Sed. = teste de sedimentação.

O teste de amilógrafo (Quadro 7), que mede a viscosidade, permite chegar às mesmas consideraçoes do "falling number". Como se esperava, as farinhas apresentaram valores altos de viscosidade máxima a quente (V.M.) acima de 700 unidades, indicando as mesmas tendências enzímicas apresentadas anteriormente. Uma viscosidade alta propicia um pão de miolo rígido devido à grande absorção de água pelo amido, formando um gel mais viscoso que, no forno, produzirá miolo mais duro. Em situação inversa, indicará alta atividade enzimática, sobrando água e resultando em pão de miolo úmido.

Dentro dessas consideraçбes, os dois cultivares mostraram valores relativamente altos, o que, evidentemente, pode ser corrigido pela adição de enzimas, como é usualmente feito na prática. 
QUADRO 7 - Características farinográficas e amilográficas da farinha de trigo dos cultivares IAC-21 e IAC-22

\begin{tabular}{|c|c|c|c|c|c|c|c|c|}
\hline \multirow{2}{*}{ Amostra } & \multicolumn{5}{|c|}{ Farinografo } & \multicolumn{3}{|c|}{ Amilógrafo } \\
\hline & T D. & $\mathrm{R}$. & E. & A & $\mathrm{Ab}$. & T.G. & V.M. & T.V.M. \\
\hline & $\min s$ & $\min \mathrm{s}$ & $\min \mathrm{s}$ & U.F. & $\%$ & ${ }^{\mathrm{O}} \mathrm{C}$ & U.A. & ${ }^{\circ} \mathrm{C}$ \\
\hline IAC-21 & 300 & 430 & 130 & 60 & 56 & 60,0 & 1630 & 90 \\
\hline IAC-22 & 300 & 430 & 130 & 60 & 56 & 61,5 & 1560 & 90 \\
\hline
\end{tabular}

T.D. = tempo de desenvolvimento; $\mathrm{R}=$ resistência $=\mathrm{E}+$ T.D. $\mathbf{E}=$ estabilidade $; \mathrm{A}=$ abrandamento em unidades farinográficas Brabender (U.F.); Ab. = absorção; T.G. = temperatura de gelatinização; V.M. = viscosidade máxima; T.V.M. = temperatura de viscosidade máxima.

Ainda no quadro 7 , os resultados da análise no farinógrafo revelam que não houve diferença en tre uma variedade e outra.

Resultados do quadro 8 indicam que ambos os cultivares, em relação à produção e retenção de $\mathrm{CO}_{2}$ pela massa, possuem praticamente as mesmas características, pois seus valores são muito próximos entre si. Com relação, entretanto, à extensibilidade da massa após 135 minutos de descanso, o cultivar IAC-21 apresentou-a um pouco maior do que o 'IAC-22'; entretanito, este mostrou melhor resistência à deformação, indicando ter reação mais favorável à adição de melhoradores do tipo oxidante (BLOKSMA, 1964).

QUADRO 8 - Características expansográficas e extensográficas da farinha de trigo dos cultivares IAC-21 e IAC-22

\begin{tabular}{|c|c|c|c|c|c|c|}
\hline \multirow{2}{*}{ Amostra } & \multicolumn{4}{|c|}{ Extensógrafo } & \multicolumn{2}{|c|}{ Expansógrafo } \\
\hline & $\begin{array}{c}\text { R. } \\
\text { U.E. }\end{array}$ & E. & $\mathrm{Ra}$. & A. & C.R. & Es. \\
\hline & & $\mathrm{cm}^{2}$ & - & \\
\hline IAC-21 & 405 & 175 & 20,8 & 162,9 & 58,5 & 48,0 \\
\hline IAC-22 & 625 & 136 & 4,6 & 137,2 & 60,0 & 43,0 \\
\hline
\end{tabular}

R. = resistência em unidades extensográficas; E. = extensibilidade; Ra. = razão; A. = área; C.R. = capacidade de retenção de $\mathrm{CO}_{2} ;$ Es. = estabilidade de $\mathrm{CO}_{2}$. 
Infelizmente, nenhum dos métodos reológicos ou químicos empregados sozinhos até o momento é capaz de prever exatamente a característica final do produto a ser preparado por uma farinha de trigo. Esses critérios são apenas indicadores de tendências. Assim, o teste de panificação proporciona uma visão mais real do comportamento de uma farinha, pois todos os ingredientes estão agindo ao mesmo tempo no processo. Os resultados do quadro 9 revelam claramente que o pão obtido com a farinha do trigo 'IAC-22' apresentou volume específico comparativo maior do que o 'IAC-21', indicando produto mais leve e um pouco superior.

QUADRO 9 - Características dos pães obtidos com farinha de trigo dos cultivares IAC-21 e IAC-22

\begin{tabular}{lcc}
\hline Amostra & V.E.C. & C.T.C. \\
\hline & $\%$ & $\%$ \\
IAC-21 & 109 & 102 \\
IAC-22 & 117 & 102 \\
\hline
\end{tabular}

V.E.C. $=$ volume especifico comparativo a farinha de trigo comercial $($ V.E. $=100 \%$ ) C.T.C. $=$ contagem total comparativa a farinha de trigo comercial $($ C.T. $=100 \%)$.

Quanto às características internas e externas do pão, como extura, cor de miolo, sime tria e cor externa, não houve diferença en tre as duas amostras.

\section{CONCLUSÕES}

1. Os cultivares de trigo IAC-21 e IAC-22 apresentaram maior produtividade de grãos que as testemunhas IAC-5 e BH-1146, nos anos em estudo.

2. O 'IAC-22' apresentou resistência a maior número de raças de ferrugem-do-colmo do que o 'IAC-21', e ambos sempre apresentaram menores níveis de infecção do que as testemunhas em condiçðes de campo. Com relação à ferrugem-da-folha, esses cultivares foram suscetíveis às raças do patógeno prevalecentes no Estado de São Paulo.

3. Comparativamente à farinha de trigo comercial, os dois cultivares tiveram desempenho levemente superior, em panificação, sendo que o 
IAC-22, de maneira geral, foi de melhor potencial. Portanto, ambos podem ser utilizados, do ponto de vista do uso tecnológico, para produção de farinha e esta para panificação.

\section{SUMMARY}

IGUAÇU (IAC-21) AND ARAGUAIA (IAC-22) - WHEAT CULTIVARS FOR UPLAND CONDITIONS OF THE STATE OF SÃO PAULO, BRAZIL

Two new selected germoplasms of wheat (Iguaçu and Araguaia) were tested against two commercial varieties (BH-1146 and IAC-5) for y ield and resistance to stem and leaf rusts in several experiments carried out in different locations of the wheat areas of the State of Sao Paulo, Brazil, in the period 1978-1982. Cultivar Iguaçu produced $8 \%$ and $12 \%$ more grain per hectare in comparison with respectively, cultivars BH-1146 and IAC-5; cultivar Araguaia had, respectively, 5\% and 14\% more grain yield than the same commercial varieties. Iguaçu and Araguaia cultivars presented less stem rust infection than BH-1146 and IAC-5 while Araguaia had a lower infection level than Iguaçu under field conditions. It was not observed differences in resistance to leaf rust among them. Araguaia exhibited better bread qualities than Iguaçu but both showed better qualities than the used commercial wheat flour.

Index terms: wheat cultivars; grain yield; rust resistance; rust physiologic races; bread qualities.

\section{REFERÊNCIAS BIBLIOGRÁFICAS}

ALLARD, R.W. Principles of plant breeding. New York, John Wiley, 1960. $381 \mathrm{p}$.

AMERICAN ASSOCIATIONS OF CEREAL CHEMISTS. Methods of Analysis of AACC. St. Paul, Minn., 1969.

ARBEITSGEMEINSCHALT fuer Getreidefosghung Standart fuer Getreide und, Brot. Detmold, Ed. Moritz Schaefer, 1971. 138p.

BÄR, W.H. Análise e avaliação do trigo e dos produtos derivados. Campinas, ITAL, 1982. 154p.

BARCELLOS, A.L. As ferrugens do trigo no Brasil. In: FUNDAÇÃO CARGILL. Trigo no Brasil. Campinas, 1982. v.2, p.375-420.

BAYMA, A. da C. Trigo. Rio de Janeiro, Ministério de Agricultura, Serviço de Informação Agrícola, 1960. 2v. (Estudos Técnicos, 14)

BLOKSMA, A.H. Rhealogy an chemistry of dough. Ju Pomeramz, wheat chemistry and technology. St. Paul, Minn., AACC, 1964. 821 p. 
CAMARGO, C.E.O. Estudos de variedades de trigo para o Estado de São Paulo. Piracicaba, Escola Superior de Agricultura "Luiz de Queiroz", 1972. 102p. Tese. (Doutoramento)

\& OLIVEIRA, O.F. Tolerância de cultivares de trigo a diferentes níveis de alumínio em solução nutritiva e no solo. Bragantia, Campinas, 40:21-31, 1981.

COELHO, E.T. Ferrugem-do-colmo do trigo: levantamento de raças em 1980,1981 e 1982 (parcial) e testes de resistência dos cultivares dos ensaios Norte-Brasileiros. In:REUNIÃO DA COMISSÃO NORTE BRASILEIRA PESQUISA DE TRIGO, 9., Brasília, DF, 1983. 8p.

Variedades e melhoramento. In:FUNDAÇÃO CARGILL. Trigo no Brasil. Campinas, 1982. v.1, p.145-98.

FELÍCIO, J.C.; BARROS, B.C.; CAMARGO, C.E.O. \& BÄR, W.H. Maracaí (IAC-17) e Xavantes (IAC-18), cultivares de trigo para o Estado de São Paulo. Bragantia, Campinas, 42:15-25, 1983.

GOMES, F.P. Curso de estatística experimental. Piracicaba, Escola Superior de Agricultura "Luiz de Queiroz", 1963. 384p.

SCHRAM, W.; FULCO, W.S.; SOARES, M.H.G. \& ALMEIDA, A.M.P. Resistência de cultivares de trigo em experimentação ou cultivo no Rio Grande do Sul, às principais doenças fúngicas. Agronomia Sul rio-grandense, Porto Alegre, 10:31-39, 1974.

TEIXEIRA, E.F. O trigo no sul do Brasil. São Paulo, Editoria Linotype, 1958. 300p.

VITTI, P.; LEITÃo, R.F.F.; PIZZINATTO, A. \& PENTEADO, R.L.B. Preparo de uma farinha de milho integral e desengordurada e seu uso em produtos de panificação. Boletim do ITAL, Campinas, 17(4): 45 1-67, 1980.

; MOREIRA, R.T. \& BÄR, W.H. Estudo tecnológico do cultivar de trigo nacional IAC-18 BA. Boletim do ITAL, Campinas, 19(2):183-94, 1982. 